\title{
SEEING THE TREES WITHIN THE FOREST: CONTEXTUALIZED ETHICS COURSES AS A STRATEGY FOR TEACHING LEGAL ETHICS
}

\author{
THOMAS B. METZLOFF*
}

\section{INTRODUCTION}

The programs supported by the William M. Keck Foundation were designed to develop and test different models for teaching ethics within law schools. Two basic approaches predominate: (1) invigorating the traditional, required ethics course, and (2) attempting to "mainstream" ethical issues in the myriad of other substantive law courses. Although both approaches are valid, a strategy focused solely on upgrading or mainstreaming existing required courses has limits. At Duke Law School, the option of significantly changing our required ethics course was not immediately available. For the past decade, we have been teaching the required course in an intensive one-week format during the first year of law school. ${ }^{1}$ This approach has some distinct advantages, most notably the high interest level that first-year students exhibit in their chosen profession. But the constraints inherent in such a format are obvious: there is limited time to develop themes or explore the subtleties of ethical issues. Also, first-year students' substantive knowledge of the law is limited, which restricts their ability to engage hypotheticals on a realistic level. Thus, during the week-long course, we can do little more than introduce students to the basic structure of ethical rules and explore a few selected topics of general interest.

"Mainstreaming," or the pervasive use of ethics materials in other substantive courses, is undoubtedly useful for it will make clear to law students that ethical considerations should be routinely considered. But, again, there are inherent limits to the depth of the treatment that can be achieved in a substantive course. The law is increasingly complex; faculty already face significant pressure to pick and choose among numerous topics of substantive law. Adding an ethics component merely exacerbates these pressures. Moreover, either because of a lack of interest or knowledge, some faculty members are unwilling to commit substantial time to ethical issues.

Copyright () 1996 by Law and Contemporary Problems

* Professor of Law, Duke University.

1. For a brief description of the course and its approach, see James L. Oakes, Commentary on Judge Edwards' "Growing Disjunction Between Legal Education and the Legal Profession," $91 \mathrm{MICH}$. L. REV. 2163, 2163-65 (1993). 
For these reasons, the approach adopted at Duke did not attempt a radical revision of the required ethics course or the development of ethical components or sub-units for substantive courses. Rather, our objective was to develop a broad array of advanced courses and seminars that directly deal with ethical problems that arise in specific lawyering contexts, such as civil or criminal litigation, or actions before regulatory agencies. Inherent in this pedagogical approach is an assumption that while there are overlapping considerations across various practice areas, the ethical issues faced by lawyers in these different contexts vary to a considerable extent. Rather than attempt to compare and contrast these differing concerns, our objective was to embrace the differences.

This article reports on our efforts to pursue this pedagogical development. Primarily, it describes my effort to design a specialized ethics course for the field of civil litigation and contrasts this specialized course approach with an alternative strategy of trying to instill greater ethical content in the traditional civil procedure course. The article then briefly canvasses other lawyering contexts in which faculty at Duke Law School have offered advanced ethics offerings. The article concludes with a brief reflection on the strengths and weaknesses of the specialized course approach.

\section{II}

\section{AN EXAMPLE: ETHICAL IsSUES IN CiviL Litigation}

An initial question in developing a specialized ethics offering is whether there is sufficient content to carry a semester-long course. For the purpose of this article, a more important question is whether exposure to one particular slice of the ethics world-without elaborate consideration of other ethical challenges raised in other areas of legal practice-is desirable. The extensive description of the course I developed on ethical issues in civil litigation provides a basis for answering these questions.

To be sure, certain ethical concerns are not as well addressed in the civil litigation context as in others. For example, the challenges of disclosure of confidential information or the appropriateness of withdrawal as an ethical response are almost certainly better analyzed in the context of the corporate lawyer, who may become aware of information that if not disclosed may seriously injure someone. ${ }^{2}$ Litigation, on the other hand, tends by its nature to be retrospective in most instances; the problem has already occurred, and thus certain types of confidentiality problems are minimized. Similarly, the growing recognition of conflict of laws questions relating to ethical issues has not yet

2. See ABA Comm. on Ethics and Professional Responsibility, Formal Op. 366 (1992) (withdrawal when a lawyer's services will otherwise be used to perpetrate a fraud); Stephen Gillers, Model Rule 1.13(c) Gives the Wrong Answer to the Question of Corporate Counsel Disclosure, 1 GEO. J. LEGAL ETHICS 289 (1987). 
proven to be of great significance for litigators. ${ }^{3}$ Nevertheless as detailed below, the civil litigation context provides a superb sounding board for a wide array of challenging ethical problems.

\section{A. Exploring the Culture of Litigation}

I begin the course with an overview of the "culture of litigation." Admittedly, this overview is somewhat problematic; regional variations in litigation-related cultural norms, even if identifiable, complicate any systematic study. The primary readings present contrasting stories of lawyers handling various matters: the first about an attorney who is clearly committed to the "pure form" of the adversarial process, ${ }^{4}$ the other about an attorney who is apparently more concerned with broader societal goals. ${ }^{5}$ Students are encouraged to share examples they have encountered that describe typical litigators. We also look at how litigators have been depicted in popular films and novels. All of this is related to the central goal of the course: to examine critically the power and desirability of the adversarial ethic.

\section{B. Origins, Structure, and Purpose of Ethical Rules}

After the overview session, I find it necessary to provide by way of review a reintroduction to the formal ethical rules and their origins. To keep this review exercise in context, I highlight specific provisions from earlier codes of legal ethics that bear directly on important litigation-related issues. By focusing on the historical origins or manifestations of the adversarial process, one can both review the structure of codes and develop some insights into how ethics rules define or limit the culture of litigation. For example, I ask students to react to assigned excerpts from David Hoffman's 1836 Resolutions in Regard to Professional Deportment by indicating which rules they find anachronistic,

3. Cf. Stephen B. Burbank, State Ethical Codes and Federal Practice: Emerging Conflicts and Suggestions for Reform, 19 FORDHAM URB. L. J. 969 (1992) (describing the "increasingly troublesome" problems of disuniformity created when federal court rules incorporate state or bar association norms of professional conduct).

4. The particular story I use is the account of a malpractice trial conducted by well-known Chicago attorney Philip Corboy contained in JOHN A. JENKINS, THE LITIGATORS: INSIDE THE POWERfUL WORLD OF AMERICA'S HIGH-STAKES TRIAL LAWYERS (1989). One of my favorite passages in the account quotes Corboy as follows:

I have a weakness as a cross-examiner: activism. When I'm on a roll, I've got a tendency to brutalize. My business, bottom line, is to win. Sometimes it takes a stiletto rather than a guillotine! I have to be constantly on guard, constantly aware that crucifixion of every witness is not a necessity! . . . Winning isn't everything, it's the ONLY thing! There are no excuses for losing. Every time I've ever had any semblance of failure, I've said to myself, on reflection, "There are lots of lawyers who could have done better than I." And that's what the client's entitled to get. He's entitled to get the best, and if I can't give it to him I shouldn't be in the case!

Id. at 353 .

5. See Steven Lubet, Professionalism Revisited, 42 EMORY L. J. 197, 206-08 (1993) (describing the positive impact of the presence of well-respected lawyer Albert Jenner handling a case in an usually chaotic landlord-tenant and collection court). 
enlightening, naive, or otherwise noteworthy. ${ }^{6}$ Several of Hoffman's "rules"-such as the rule against asserting "technical" defenses such as the statute of limitations ${ }^{7}$ are clearly contrary to modern sensibilities and elicit interesting reactions. For the more modern codes, it is useful to explore briefly the drafting process to understand the political nature of these documents. ${ }^{8}$ A central goal of any ethics course must be to learn to read the rules rigorously and critically.

\section{Critically Examining the Theory of the Adversarial Process}

For all the supposed dedication our litigation system has to the ethic of the adversarial process, most students know little about its origins. It is often simply assumed that "this is the way it is." Accordingly, some exposure to its historical roots is necessary for a reasoned consideration of its validity as a workable paradigm. ${ }^{9}$ Beyond that, it is fair to spend some time reading those who defend the faith of the adversarial system, ${ }^{10}$ including those who attempt to justify its possible excesses.

However, one must also acknowledge that the current procedural system is not totally accepting of the adversarial ethic. Indeed, it is fair to ask whether we in fact have an adversarial process, as is so commonly assumed. In answering this inquiry, one profitably can consider key civil procedure developments, such as the new disclosure rules that replace (at least in those districts that are using them) portions of the discovery process. Other changes, including the evolution of judicial authority to manage cases, open-ended discovery, alternative dispute resolution, and the trend toward judicial authority to sanction attorney misconduct make it abundantly clear that our civil procedure system is far less committed to a system of adversarial ethics than is commonly thought. ${ }^{11}$ Existing ethics opinions, for example, provide that lawyers are not to take advantage of an opposing party's inadvertent disclosures of confidential information during the discovery process. ${ }^{12}$

6. David Hoffman, A Course of Legal Study, AdDressed to Students and THE PROFESSION GENERALLY 752-75 (2d ed. 1836) (setting forth 50 "resolutions in regard to professional department").

7. Id. at 754

8. See Edward L. Wright, The Code of Professional Responsibility: Its History and Objectives, 24 ARK. L. REV. 1 (1970).

9. On the topic of the history of the adversarial process, see Ellen E. Sward, Values, Ideology and the Evolution of the Adversary System, 64 IND. L. J. 301 (1989).

10. For an excellent description of the power of the adversary ethic in the American litigation culture, see Geoffrey C. Hazard, Jr., The Future of Legal Ethics, 100 YALE L. J. 1239 (1991).

11. See Judith Resnik, Failing Faith: Adjudicatory Procedure in Decline, 53 U. CHI. L. REV. 494, 526-39 (1986); see also Judith Resnik, Managerial Judges, 96 HARV. L. REV. 376, 380-403 (1982). To make these discussions meaningful, I have found it necessary to provide quick reviews of recent civil procedure trends.

12. E.g., ABA Comm. on Ethics and Professional Responsibility, Formal Op. 368 (1992) (inadvertent disclosure of confidential materials). 


\section{The Alternative to the Adversarial Process: Exploring the "Officer of the Court" Paradigm}

If one is critical of the adversarial process, what is the alternative? One competing notion is that of the lawyer as "officer of the court." This model is frequently alluded to by those interested in reforming litigation ethics, but what does this phrase mean in practical terms? Is the "officer of the court" formulation a workable counterbalance to the perceived excesses of the adversarial process? ? $^{13}$ Numerous specific examples can be examined that pit the adversarial model against a possibly opposing "officer of the court" paradigm. One that nicely focuses the inquiry is how attorneys should deal with lying clients. Most ethics courses simply present this issue through the context of the leading criminal law case of Nix v. Whiteside. ${ }^{14}$ However, the issues are arguably different in the civil context, and thus deserve separate analysis. ${ }^{15}$ Another example of the tension is highlighted by the lawyer's duty to cite potentially adverse authority to the court. Under the adversarial ethic, the responsibility is that of the opponent and, failing that, the court itself. Adopting an "officer of the court" model would place greater responsibility on the advocate to cite adverse authority fairly. ${ }^{16}$

The "officer of the court" approach also raises interesting questions as to lawyers' obligations to uphold the dignity of the court and third parties. Should litigators receive the broad immunity for defamatory statements made in the course of litigation that American courts currently provide them ${ }^{17}$ What obligations should attorneys have to avoid discrimination even if such actions

13. For the best analysis of the "officer of the court" model, see Eugene R. Gaetke, Lawyers as Officers of the Court, 42 VAND. L. REV. 39 (1989). If more adventuresome, other models exist, and time can profitably be spent discussing these more radical reformulations of legal ethics. See, e.g., William H. Simon, Ethical Discretion in Lawyering, 101 HARV. L. REV. 1083 (1988). A related issue is whether lawyers employed by the government have heightened ethical responsibilities. See, e.g., Catherine J. Lanctot, The Duty of Zealous Advocacy and the Ethics of the Federal Government Lawyer: The Three Hardest Questions, 64 S. CAL. L. REV. 951 (1991).

14. 475 U.S. 157 (1986).

15. See ABA Comm. on Ethics and Professional Responsibility, Formal Op. 353 (1987); Steven H.

Goldberg, Heaven Help the Lawyer for a Civil Liar, 2 GEO. J. LEGAL ETHICs 885, 891-95 (1989).

16. See Geoffrey C. Hazard, Jr., Arguing the Law: The Advocate's Duty and Opportunity, 16 GA. L. REV. 821, 825-29 (1982); Jeffrey M. Smith \& Thomas B. Metzloff, The Attorney as Advocate: “Arguing the Law," 16 GA. L. REV. 841, 846-48 (1982).

17. For a discussion of the current immunity provided, see Paul T. Hayden, Reconsidering the Litigator's Absolute Privilege to Defame, 54 OHIO ST. L. J. 985 (1993). 
serve their clients' interests? ${ }^{18}$ To what extent should attorneys be able to criticize judges openly? ${ }^{19}$

More generally, exploring the "officer of the court" paradigm forces students to consider the extent of their obligations as public citizens. ${ }^{20}$ Recently, this issue has come to the surface in the efforts by several states to encourage, and in some cases require, lawyers to provide pro bono services. ${ }^{21}$ While not an issue that is uniquely presented in the litigation context, the policy issues are capable of being fully explored.

\section{E. Discovery Abuse, Civility, and the Rule 11 Issue}

The numerous issues and problems combined under the general heading of "discovery abuse" are central to any serious study of the ethics of civil litigation. ${ }^{22}$ One pivotal aspect of this topic is the range of issues generally identified by growing concern with the civility of lawyers. It is a challenge to explore the "civility" movement, in part because the students lack the experience needed to gauge the basic assertion that lawyers are increasingly less civil. $^{23}$ Nonetheless, the possible reasons for declining civility can be explored as well as the potential impact that civility codes might have on the problem. The civility movement also provides a valuable opportunity to discuss demographic changes within the profession; one possible critique of civility codes is that they represent a reactionary response to the growing diversity within the profession. ${ }^{24}$

18. The ABA is currently grappling with that issue as it considers efforts to amend Model Rule 8.4 to include a specific prohibition of discriminatory conduct. See STEPHEN GILLERS \& ROY D. SIMON, JR., REgUlation OF LAWYERS: STATUTES AND STANDARDS 1996, at 394-96 (proposed rule making it professional misconduct to "knowingly manifest by words or conduct, in the course of representing a client, bias or prejudice based upon race, sex, religion, national origin, disability, age, sexual orientation or socio-economic status," although such prohibition would not "preclude legitimate advocacy" with respect to those factors).

19. For the most interesting recent case dealing with attorney criticism of a judge, see Standing Committee on Discipline v. Yagman, 55 F.3d 1430 (9th Cir. 1995).

20. See, e.g., Timothy P. Terrell \& James H. Wildman, Rethinking "Professionalism," 41 EMORY L. J. 403 (1992).

21. GILlERS \& SIMON, supra note 18, at 313-26 (Model Rule 6.1).

22. There are ample materials discussing the types of problems usually associated with the term "discovery abuse." See, e.g., Wayne D. Brazil, The Adversary Character of Civil Discovery: A Critique and Proposals for Change, 31 VAND. L. REV. 1295 (1978). For an interesting recent discussion, see Paramount Communications, Inc. v. QVC Network, Inc., 637 A.2d 34, 52-56 (Del. 1994) (describing attorney misconduct during a deposition).

23. When the civility issue first arose, my own assessment was that it was a naive response to serious problems that had been adopted by a few bar associations or courts concerned with the vague issue of "professionalism." But the civility movement has shown remarkable staying power. See FINAL REPORT OF THE COMMITTEE ON CIVILITY OF THE SEVENTH FEDERAL JudiCIAL CiRCUIT (June 1992); Dondi Properties Corp. v. Commerce Savings \& Loan Ass'n, 121 F.R.D. 284, 292-95 (N.D. Tex. 1988) (appending copies of the Dallas Bar Association Guidelines of Professional Courtesy and the Dallas Bar Association Lawyer's Creed).

24. See, e.g., Amy R. Mashburn, Professionalism as Class Ideology: Civility Codes and Bar Hierarchy, 28 VAL. U. L. REV. 657. 670-72 (1994). 
The civility issue is but a sideshow compared to the main attraction of the utility of Rule 11 in controlling litigator misconduct. The experience with Rule 11 since its initial amendment in 1983 presents a superb case study for a host of issues of central importance. ${ }^{25}$ Its evolution is extraordinary-from a rule with no measurable impact to one that from 1983 until 1993 resulted in the sanctioning of thousands of American attorneys. Its amendment in 1983, which empowered federal judges to police the ethical norms of litigation attorneys, represented a bold experiment and a radical restructuring of our profession's understanding of lawyer accountability. That the profession balked at the effort, as evidenced by the recent 1993 amendments that reduced the likelihood of active judicial supervision, should in retrospect not be surprising. What is currently difficult to assess is the impact that the new Rule 11 will have. Views on this subject vary widely: Some view the new rule as a welcome return to the status quo; others still believe that even the watered-down version represents a major deterrent to effective advocacy; still others (like myself) believe that the new version is essentially a repudiation of a highly desirable development toward greater attorney accountability.

In the course, I try to explore aspects of the Rule 11 problem that go beyond that which was covered in Civil Procedure. The details of the rule itself are presented quickly to provide a common starting point. Interpretations of the rule (such as who is liable) are not critical in this context because the goal is to understand generally what the rule is intended to accomplish, not the details of Rule 11 practice. ${ }^{26}$ Instead, the course focuses on the rule's impact on the profession. To an extent, this involves empirical analysis. ${ }^{27}$ Beyond that, an exploration of the rule's impact on the profession involves a discussion of whether it is desirable to have active judicial control over litigation attorneys, especially plaintiff's attorneys. Additionally, my goal is to force students to focus on the impact and purpose of the 1993 revision to Rule 11-why was it changed? ${ }^{28}$ What groups supported and opposed its amendment? What impact will the new Rule 11 have on efforts to control attorney misconduct?

25. Obviously, some portion of the history and structure of Rule 11 would be considered mandatory by most civil procedure teachers. Indeed, it is a topic that most professors desire to teach in order to proclaim that they are "instilling" ethics in their substantive courses. I am not aware of any study indicating the depth in which civil procedure teachers in fact cover Rule 11 beyond studying the Rule itself and the Supreme Court cases interpreting it. My own guess is that since the 1993 revision of Rule 11 , the amount of time spent on Rule 11 in most civil procedure classes has decreased. In my view, what is missing from the coverage provided in most civil procedure texts is an analysis of the empirical evidence from which a student could assess the wildly contradictory claims offered by partisans during the 1993 amendment debates about the effectiveness of the 1983 version of the rule.

26. Possible alternative structures to Rule 11 are discussed. For a discussion of one alternative approach, see William W Schwarzer, Rule 11 Revisited, 101 HARV. L. REV. 1013 (1988).

27. For a discussion of an analytical framework and empirical data assessing Rule 11, see Stephen B. Burbank, The Transformation of American Civil Procedure: The Example of Rule 11, 137 U. PA. L. REV. 1925 (1989).

28. Amendments to the Federal Rules of Civil Procedure, 507 U.S. 1089, 1096-99 (1993) (Scalia, J., dissenting). 


\section{F. Conflicts of Interest}

Analyzing conflicts of interest issues is a central task for any serious examination of legal ethics. The conflicts rules are written generally to apply to all attorneys; applying them in specific situations requires careful application of general terms. One of the constant refrains from practitioners is that the conflicts rules provide little specific guidance. However, their structure may adequately be understood by examining the function of the rules in specific contexts. Civil litigation provides a rich area for exploration. As a practical matter, the wealth of civil litigation materials is a function of the fact that much of the law on conflicts has arisen from motions filed in civil actions to disqualify opposing counsel. As a result, while conflicts issues in other areas often require conjecture and extrapolation, litigation conflicts-such as the propriety of counsel litigating against a former client-can be analyzed with the aid of extensive case law. ${ }^{29}$ Elusive issues such as the "appearance of impropriety" can be discussed against the backdrop of actual scenarios, such as the problems created with law firm mergers. ${ }^{30}$

More systemic questions of the purpose of conflicts of interest concerns can also be identified and examined. Recently, attention has been given to the problems of "positional" conflicts of interest-a concern primarily focused on litigators-which relate to attorneys who are arguing for the adoption of a legal principle on behalf of one client, but who have past or present clients whose interests may be harmed should that legal position be adopted. In the past, most observers assumed that this sort of conflict was permissible because lawyers did not personally vouch for the validity of the legal positions they espoused. However, with the growing specialization of litigation practice, the concerns with positional conflicts have grown. ${ }^{31}$

\section{G. The Ethics of Negotiation and Settlement}

While all attorneys negotiate, civil litigation provides a rich context for analyzing the responsibility of lawyers within the negotiation process. Settlement negotiations can provide a wide range of examples of potentially troublesome tactics. The current ethics rules adopt a predominantly laissez-faire approach to regulating attorney conduct in negotiations. The rules tolerate the use of various negotiating tactics based upon an acceptance of the "cultural norms" of the legal profession and rely on other aspects of the adversarial

29. See, e.g., Crawford W. Long Memorial Hosp. v. Yerby, 373 S.E.2d 749 (Ga. 1988) (discussing propriety of lawyer who had previously handled numerous malpractice claims on behalf of hospital representing a malpractice plaintiff against the hospital).

30. See Picker Int'l, Inc. v. Varian Assoc., 869 F.2d 578 (Fed. Cir. 1989).

31. See John S. Dzienkowski, Positional Conflicts of Interest, 71 TEX. L. REV. 457 (1993); see also ABA Comm. on Ethics and Professional Responsibility, Formal Op. 377 (1993) (positional conflicts). 
process, such as party access to discovery, to ensure fairness within negotiations. 32

Not surprisingly, the current approach has been subject to considerable criticism. The problems identified are not of only theoretical concern; the incentives for lawyers to lie or engage in subterfuge during negotiations are strong. ${ }^{33}$ The general argument in favor of demanding higher ethical standards in the negotiations context was first articulated by Judge Rubin in his widely cited article from the mid-1970s where he encourages at least a minimum ethic of honesty in negotiations. ${ }^{34}$ Nonetheless, there remains substantial support for the current regime. This view challenges Rubin's proposed reforms in large part for practical reasons-how as a practical matter can an ethic of honesty be enforced even if one could articulate an appropriate standard? $?^{35}$ Negotiations take part largely in private sessions; determining who said what to whom would be difficult at best in most situations. This debate presents an excellent opportunity to discuss what continues to be a daunting aspect of the law of ethics generally: What groups or agencies are in fact going to define and enforce ethical norms? ${ }^{36}$ How important are enforcement considerations to determining appropriate standards of ethics? ${ }^{37}$ My students have been about equally divided on the desirability of articulating a stronger negotiating ethic. The challenge for those who want to do more is to articulate what goals one wants to accomplish. On this point, an historical review of the efforts to do so in the early drafts of the Model Rules and also of earlier ethics codes are instructive. ${ }^{38}$

32. For a more contemporary criticism of the current ethics rules, see Ruth Fleet Thurman, Chipping Away at Lawyer Veracity: The ABA's Turn Toward Situation Ethics in Negotiations, $1990 \mathrm{~J}$. DISP. RESOL. 103.

33. See, e.g., Gerald B. Wetlaufer, The Ethics of Lying in Negotiations, 75 IOWA L. REV. 1219, 122630 (1990) (detailing the effectiveness of lying in negotiation).

34. Alvin B. Rubin, A Causerie on Lawyers' Ethics in Negotiation, 35 LA. L. REV. 577, 590-92 (1975).

35. See, e.g., James J. White, Machiavelli and the Bar: Ethical Limitations on Lying in Negotiation, 1980 AM. BAR FOUND. RES. J. 926, 929-30, 937-38.

36. See David B. Wilkins, Who Should Regulate Lawyers?, 105 HARV. L. REV. 801 (1992).

37. This topic thus provides an excellent setting for discussing what should be the goals of a code of professional ethics given the tension between aspirational norms and a discipline-based approach. See Stephen Gillers, What We Talked About When We Talked About Ethics: A Critical View of the Model Rules, 46 OHIO ST. L. J. 243, 255, 260-62 (1985).

38. For an example of an early attempt to create a stronger negotiation ethic, see Rule 4.1. MODEL RulEs OF PROFESSIONAL CONDUCT Rule 4.1 (Discussion Draft 1980). This draft rule provided in part as follows:

As negotiator, a lawyer should consider not only the client's short-run advantage but also his or her long-run interests, such as the state of future relations between the parties. The lawyer should help the client appreciate the interests and position of the other party and should encourage concessions that will effectuate the client's larger objectives. A lawyer should not transform a bargaining situation into a demonstration of toughness or hypertechnicality or forget that the purely legal aspects of an agreement are often subordinate to its practical aspects. When the alternative to reaching agreement is likely to be litigation, the lawyer should be aware that, although litigation is wholly legitimate as a means of resolving controversy, a fairly negotiated settlement generally yields a better conclusion. A lawyer should also recognize that the lawyer's own interest in resorting to litigation may be different 
In discussing the subject, any number of useful "real world" issues can be profitably examined. For example, recently there has been much debate over the desirability of permitting parties to require confidentiality provisions in settlement agreements. $^{39}$ While probably acceptable in routine cases, the effects of confidentiality in other contexts-such as sexual abuse claims against psychiatrists-raises challenging policy issues with a distinctly ethical component on both sides of the negotiating table. For the plaintiff, the ability to threaten (whether explicitly or otherwise) to report a professional to a disciplinary authority arguably can provide unfair bargaining leverage. Indeed, claims against attorneys present the additional ethical obligation to report known misconduct under applicable professional rules. ${ }^{40}$ For the defendant, the opportunity to "buy off" the plaintiff's silence is even more troubling: Should lawyers be permitted to negotiate settlements that insist upon their clients not reporting known abusers to the disciplinary authorities? ${ }^{41}$ Specific examples of this type of conduct provide an excellent base upon which to discuss the trend toward greater confidentiality in settlement agreements and the counterresponse in some states to restrict such agreements. ${ }^{42}$

After discussing the individual lawyer's obligations in the context of negotiations, it is useful to explore the larger issue of the civil justice system's commitment to the issue of settlement. Too often, we stop our discussion of ethics at the micro level of considering how one attorney negotiates against another. Ethical considerations are clearly operating at the systemic level as well. Much has been done in the past fifteen years to force parties to consider settlement; efforts range from increased judicial authority to pursue settlement directly to the use of a panoply of alternative dispute resolution ("ADR") methods designed to facilitate (or arguably coerce) settlement. The literature is rich here on what motives inform these developments. ${ }^{43}$ Are they supported

from a client's interest in doing so.

See also HOFFMAN, supra note 6, at 758-59 (setting forth "resolutions" 19 and 22, which discuss the lawyer's obligation to respect a client's "wishes and real interests" with respect to compromise except when a client's reputation is involved as such cases "do not admit of compromise"). For an analysis of how other ethics rules impact the attorney's negotiating strategies, see Robert J. Condlin, Bargaining in the Dark: The Normative Incoherence of Lawyer Dispute Bargaining Role, 51 MD. L. REV. 1 (1992).

39. See, e.g., Confidential Settlements and Sealed Court Records: Necessary Safeguards or Unwarranted Secrecy?, 78 JUDICATURE 304, 304-11 (1995).

40. See In re Himmel, 533 N.E.2d 790 (Ill. 1988) (sanctioning attorney, who represented a plaintiff in a malpractice action against the client's former attorney, for failing to report the former attorney's misconduct).

41. For an interesting discussion of the problem, see Irwin D. Miller, Breaking the Written Code of Silence in Legal Malpractice Settlements, 6 GEO. J. LEGAL ETHICS 187 (1992).

42. See Lloyd Doggett \& Michael J. Mucchetti, Public Access to Public Courts: Discouraging Secrecy in the Public Interest, 69 TEX. L. REV. 643, 645-46 (1991).

43. See, e.g., Stephen McG. Bundy, The Policy in Favor of Settlement in an Adversary System, 44 Hastings L. J. 1 (1992); Owen M. Fiss, Against Settlement, 93 YAle L. J. 1073 (1984); Marc Galanter, The Quality of Settlements, 1988 J. DisP. RES. 55. For consideration of the issues as they relate to the growth of ADR, see Carrie Menkel-Meadow, Pursuing Settlement in an Adversary Culture: $A$ Tale of Innovation Co-opted or "The Law of ADR," 19 FLA. ST. U. L. REV. 1 (1991). 
by a changed belief in the inherent desirability of settlement or are they largely a practical reaction to burgeoning dockets?

\section{H. "Law as a Business" and Related Issues}

Usually, the phrase "law as a business" is expressed derogatorily; the law becoming more of a business is contrasted with the prior days when "law was a profession." Personally, I have never shared this basic orientation that the law becoming more business-like was a negative. Much of what is wrong with the legal profession can be traced to its lack of certain "business" attributes, such as the profession's failure to articulate an ethic of efficiency or develop strategies for decreasing the cost of legal services. Regardless of one's views, the topic of the business of law provides ample material for consideration in the litigation context. The topic of legal advertising, upon which the profession has spent so much of its attention, can be accessed well through the eyes of civil litigators. Certainly, most of the "offending" lawyers who advertise or are accused of unethically soliciting business are in fact civil litigators such as those who descend on the scene of major accidents or disasters. ${ }^{44}$ These cases provide interesting windows of opportunities for discussing issues of profound importance.

Numerous other "business" issues present interesting topics for student consideration. For example, the Supreme Court's decision in Peel v. Attorney Registration and Disciplinary Commission ${ }^{45}$ provides an excellent basis for considering how the profession should orient itself with respect to specialization. Interesting ethical concerns are also raised by various billing practices. Most students have some familiarity with the many issues raised by the common practice of hourly billing, such as the impact on the lawyers' incentives with respect to settlement and the advice they provide clients. ${ }^{46}$ Such discussions can be balanced by critical analysis of the ethical concerns raised by the routine use by plaintiff's attorneys of the contingency fee. In complex civil actions, the problems of financing litigation and its impact on the attorneys become even more profound. ${ }^{47}$

44. Most of the leading Supreme Court cases in legal advertising deal with civil litigators. See, e.g., Florida Bar v. Went for It, Inc., 115 S. Ct. 2371 (1995) (direct mail solicitation by plaintiff attorneys to injury victims); Zauderer v. Office of Disciplinary Counsel of Supreme Court of Ohio, 471 U.S. 626 (1985) (advertisement by lawyer seeking plaintiffs hurt by Dalkon Shield).

45. 496 U.S. 91 (1990).

46. ABA Comm. on Ethics and Professional Responsibility, Formal Op. 389 (1994) (discussing variety of unethical billing arrangements); id., Formal Op 379 (1993) (discussing validity of contingency fees in cases in which liability is not seriously contested); William G. Ross, The Ethics of Hourly Billing by Attorneys, 44 RUTGERS L. REV. 1 (1991).

47. See Vincent R. Johnson, Ethical Limitations on Creative Financing of Mass Tort Class Actions, 54 BROOK. L. REV. 539 (1988). Case law in this area also provides challenging examples. Compare In re "Agent Orange" Product Liability Litigation, 611 F. Supp. 1452 (E.D.N.Y. 1985) (upholding financing arrangement that paid "investing" attorneys three times their investment even though it reduced the amount to be received by the attorney who had done the lion's share of the work) with In $r e$ "Agent Orange" Product Liability Litigation, 818 F.2d 216 (2d Cir. 1987) (invalidating same arrangement). 
$* * * * *$

Like all courses, my goals with respect to the seminar continue to evolve. Having now taught the course three times, I continue to find new material to enrich the basic outline described above. It is a course I enjoy teaching, and which, according to their evaluations, students enjoy taking. I do not believe that the material could be adequately covered by increasing the number of ethical issues covered during the first-year civil procedure course. Much of the benefit of the in-depth discussions relates to the students' sharing of their own experiences as summer associates with such concerns as discovery abuse and the excesses of the adversarial process. While a few first-year students might have some relevant experience upon which to draw, most will not.

\section{III}

\section{REFLECTIONS ON THE SPECIALIZED APPROACH}

The advanced civil litigation seminar was by no means the only specialized ethics course offered at Duke Law School. During the past three years, approximately one-third of Duke's tenured faculty, along with several of our adjunct faculty, have taught an upper-level ethics course supported by the Keck Foundation. Over ten specialized courses have been offered. Many were, like the litigation example described above in detail, "contextualized" offerings that focused discussions on a particular area of legal practice. Such courses included examinations of ethical issues faced by lawyers principally involved in particular fields such as administrative law, ${ }^{48}$ corporate law, criminal law, and family law. Other courses focused on the ethical issues faced by particular groups of lawyers, such as those employed by the government. Another course provided students with an introduction to and appreciation for the special responsibilities of judges within our system of justice.

Overall these courses have been popular, ${ }^{49}$ although a formal evaluation of the entire group of classes has not yet been completed. Student interest has been high; the majority of the courses, typically seminars, were overenrolled. Overall, more than one-third of the 1995 graduating class took one or more of the advanced ethics offerings.

Another tangible benefit was the impact on the faculty who taught the courses. In my discussions with them, the faculty repeatedly noted the perceived benefit of having immersed themselves in the subject-matter. One

48. This course focused primarily on the myriad of ethical concerns raised by the recent savings and loan crisis. See Laborers in Different Vineyards? The Banking Regulators and the Legal Profession (ABA 1993)(Lawrence Baxter, Reporter). See also Lawrence Baxter, Reforming Legal Ethics in a Regulated Environment: An Introductory Overview, 8 GEO. J. LEGAL ETHICS 181 (1995).

49. The student evaluations from the Ethical Issues in Judicial Decision-Making course were especially strong. One student noted that the course was "probably the most consistently interesting and important course $I$ have taken in my five semesters at Duke. The judges were amazing resources and terrific instructors. PLEASE continue this course (preferably with these judges)." Another remarked that the judges were "inspirational." 
faculty member reported that the course forced her, for the first time, to read the Model Rules in their entirety, a process she found quite revealing. Most faculty believed that the challenge of preparing a new course, often out of whole cloth, was an important exercise providing greater insight into the ethical issues of moment than would have been afforded by "cutting and pasting" to add a few ethical issues within the confines of their traditional courses. The immersion in the specialized course provided greater confidence in their proficiency to deal competently with ethical questions. Moreover, having run the gauntlet of designing a specialized course, faculty members were better able to pick and choose those ethical issues that they believed would be most suitable to include within the confines of their substantive courses. The somewhat unexpected benefit of our specialized approach may well be that we achieve a greater long-range commitment to "mainstreaming" than would have been achieved if we had focused on that as our primary goal.

Several questions do present themselves, however, in evaluating the specialized approach. Perhaps the most important is how feasible is it for any law school to make such a significant commitment to offering a host of courses, even in such an important area as ethics? Even with the significant commitment we made with the generous help of the W.M. Keck Foundation, only a portion of our students took an advanced ethics course. Is such an expenditure justified? If the goal were to require all students to take such an advanced offering, it is obvious that significant additional resources would be required. Will faculty members, perhaps willing to teach a seminar to develop their own understanding of how ethical issues relate to their area of expertise, continue to be interested in teaching such courses on a regular basis?

\section{IV \\ CONCLUSION}

The Duke Law School approach to teaching ethics through a set of advanced ethics offerings is not necessarily an argument against trying to "mainstream" legal ethics. Rather, it is a different model designed to accomplish the same goal: providing a strong base of ethical training for our law students in meaningful and relevant ways. Both models require a dedicated and interested faculty willing to expand their teaching interests. For the faculty member who undertakes the challenge of teaching a specialized course in ethics and who as a result is immersed in the ethical issues relevant to his or her work, the rewards are potentially greater than those offered by adding a few ethical issues to their existing substantive courses. 
